\title{
Technology Platforms: Joining Forces, Establishing Dialogue
}

Marina Muravieva

The Russian government has begun creating a series of Technology Platforms (TPs). These platforms are meant to serve as a tool that should help close the gap between science and industry, encourage innovation at enterprises, and allow the government to focus its financial resources on the type of research and development that is of interest to business. The Ministry of Economic Development has issued a request for applications from initiators of TP development, and the government will determine the number of TPs based on the results of a selection process led by experts.

$\mathrm{N}$ ominally, the workgroup of the Governmental Commission on High Technologies and Innovations headed by Andrey Klepach, the deputy minister of economic development, is responsible for the formation of the federal panel of Technology Platforms. The idea of establishing a federal panel of TP was borrowed from the European Union, where such platforms have been in existence for several years. The Russian Ministry of Education and Science and the Ministry of Economic Development are responsible for the regulatory aspects of the process, and the Ministry of Industry and Trade actively participates in the preparation of the panel. The Russian government sees the TPs as the tool that will help link the efforts of the state, business, and science in addressing innovation challenges, as well as in setting and pursuing longterm scientific and technological priorities across different sectors of the economy, at the junction of different industries.

The term "Technology Platform" has, therefore, been a permanent fixture in documents of the European Commission for quite some time. Experts say that the fact that Russia has decided to create something similar should be welcomed and supported, It is necessary to bring representatives of business and researchers onto one platform in order to encourage a dialogue between them and identify what they have in common and their interests. That was the thinking behind the creation of TPs in the European Union. As a result, the thrust of many scientific research groups in Europe has been toward satisfying the needs of their domestic consumer markets.

Andrey Klepach, the deputy minister for economic development, said during a governmental commission in early August that

The Government assumes that

"Technology Plafforms" are a

communicative tool for enhancing efforts in:

the creation of promising commercial technologies, novel products/services,

- the attraction of additional resources for research and developments involving all interested participants (business, science, government, civil society) the field of scientific-technological and innovation development.

\section{REFERENCE:} improving the legal framework in the TPs should help solve several important tasks in Russia, the first of which is to bolster innovation at enterprises, The creation of the TP is a logical step in the development of a private-public partnership in research and development, innovation, and high technology. The TPs will gauge the interest future users (consumers) might show for the created technologies, making it easier to raise funds from private sources. Another goal, which should be taken up by the government using the TPs, is to channel government resources toward research and development, which are both in demand by business. This is extremely important, because the framework of the national innovative effort is unbalanced. The state is the main customer and the purveyor of funds for innovative development; it contributes about $70 \%$ of investments, while the private sector only contributes $30 \%$. To reverse the situation, the government is launching a process of "necessity of innovation," requiring private companies (so far only those in which the state has a stake) to plan their innovative development. It is likely that the TPs that are in the TP federal register will be linked to these plans.

\section{STATE BUDGETARY FUNDING - THROUGH PLATFORMS}

The new government initiative to create TPs has sparked a great interest in the professional community. This is easy to explain; it is assumed that after a while serious budgetary funding will only be allocated through TPs.

"TPs are considered by the government to be an important element in the reform of the scientific and applied sectors," says Alexey 


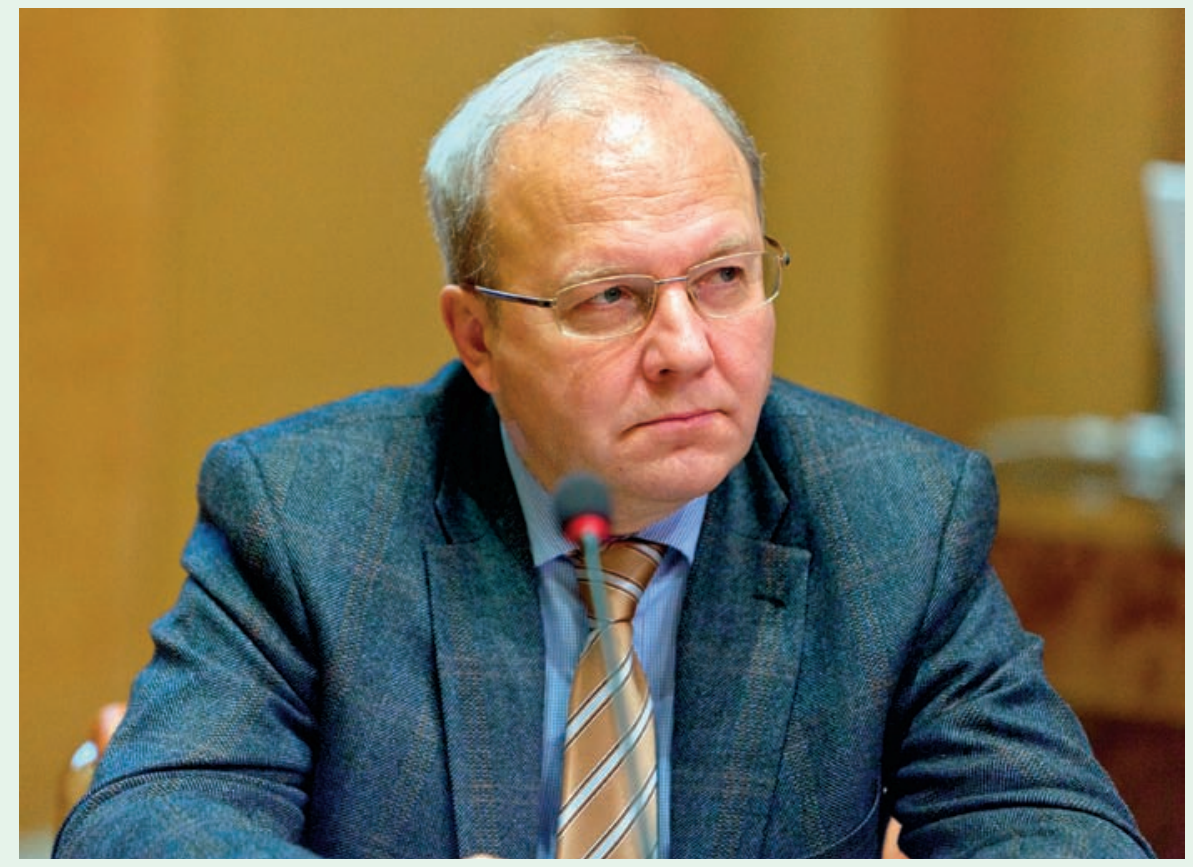

Alexey Khokhlov

Khokhlov, vice-rector in charge of innovation at Moscow State University. In particular, it is assumed that the bulk of funding to be allocated through grants will be channeled through the TPs. TPs should be regarded as a global expert platform that will determine the direction favored by business and the scientific community. What these TPs will do is help scientists formalize their projects and describe them using language that is clear to business. "If Russian TPs are made similar to European ones, then they could be the platforms that provide a certain set of documents, foresight, certain proposals, and plans. These platforms will be advisory. This is a great collective intellectual resource," says Vladimir Popov, director of the Bach Institute of Biochemistry, Russian Academies of Science.

There will be many TPs, and each one will compete for funding in certain fields. The state has identified certain areas of priority, whereas the remaining fields would receive funding only if self-organized communities of experts are sufficiently representative and able to convincingly lobby their interests.

"I still do not understand the work of TPs very well," said Academician Vsevolod Tkachuk, dean of the Department of Fundamental Medicine, MSU, "but I think success would depend on the business and research teams involved." The question is whether a TP can gain credibility and influence the competition for project funding. In previous years, calls for competition were opened by another mechanism, and it was sometimes unclear as to why the government believed one area to be more important than others. Now the government has explained that the chosen area is proposed by the $\mathrm{TP}$, not an individual. And every scientist that is a TP participant is able to convince his colleagues that the call should be opened for the given field. I believe that this would be another important mechanism supporting scientific projects."

There will be a transitional period that will last about a year or two until the platforms are fully formed. For now, another particular tool will be used in the allocation of funds.

\section{HOW TO SET PRIORITIES}

Given the European experience, one can distinguish three stages in the development of a platform. A concept is to be developed in the first stage, explaining why the TP is necessary in a given field. In Europe, they are all initiated by big business. The strategic plan for research and development that needs to be developed is determined in the second stage. The methods for transforming research and development, and the probable results that could be achieved after 3-7 years of work on the projects supported by the TP, are to be determined in the third stage.

The main issue generating much controversy in the discussion of TPs for Russia is associated with the choice of priorities. Deputy Head of the Department of Priority Projects in Science and Technology at the Ministry of Education of the Russian Federation Mikhail Puchkov believes that it is important not to focus on solving small-scale industry problems. In economics, the boundaries between industries are increasingly blurred; therefore, the focus of the TPs should be on interdisciplinary problems. The question is: What are these problems?

"I see the technology platforms as a giant funnel involving a huge amount of resources, thus depriving them of other interesting programs,

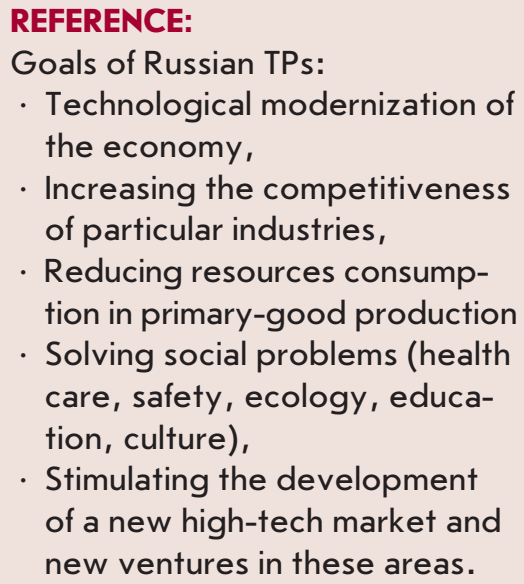


says Alexander Smirnov, general director of the Association of MilitaryIndustrial Complex Manufacturers of Medical Devices and Equipment. "Could it occur that Russia, while engaged in the creation of TPs, will fall behind in many strategically important areas, only because promising developments would be out of the scope of the platforms?"

The experts and initiators of the first TPs agree that such risks always exist when setting priorities. However, they are certain that the implication of partners from the business community should at least halve the risks. Besides, expert TP groups should be carefully built this will be the first stage in the TP creation. This process must be approached carefully. The experts have to determine which basic technologies would underline the TPs. This strictly limited list will be recorded in the passport of the platform. The competent and coordinated work of the platform experts will help avoid the duplication of studies that are funded from different sources.

\section{FIRST INITIATIVES}

Basic Principles of technology platform:
- Clear direction toward serving the interests of society, business, the state;

- Significant representation of business (a minimum of 50 percent);

- Middle- and long-term oriented projects;

- Formation of educational programs for staff training and retraining;

- Orientation on the expansion of cooperation; openness, publicity.

The Lomonosov Moscow State University made a focal point for the creation of four TPs within the limits of the development program for the innovative framework, which has been developed according to Government Regulation 219. The work at the university was launched as early as this spring. Alexey Khokhlov has stressed that MSU only plays the role of a coordinator; however, there are no "major" or "minor" participants. All participants are equal. A TP represents a voluntary association of organizations of any ownership type, governmental or nongovernmental agencies, professional associations, and professionals who share the goals and objectives of the platform. The issue of organizations joining a platform has not been formalized on legal grounds yet. Besides, the creation of a TP is a dynamic process, and the lists of participants remain open or will be created.

The first-proposed TP is "Strategic Information Technologies." Several large areas are determined in the framework of this platform. One of them is devoted to the creation of new computer architectures for exaflop generation calculators (the next generation of computing power). The second is devoted to hybrid architectures; the third, to engineering calculations, such as the design of various mechanisms. Other directions are associated with distinct industrial branches, particularly with pharmacology (development of physiologically active substances), the oil and gas industry, and materials (prediction/calculations of material characteristics based on their molecular structure).

The second TP is "Nanomaterials for Energy Efficiency." This refers to solar panels, fuel cells, new types of batteries and energy storage, "smart home" materials, and polymer nanocomposites for transport that will make electric cars or planes lighter.

\section{Alexey Konov, Executive Director, The Bioprocess Group.}

My opinion is that everybody looks at the TPs based on their own point of view: employees of the Russian Academy of Sciences (RAS) and universities understand it to be a new source of funding, like the Federal Target Program; officials in the ministries see it as a mixture between foresight and an at-

tempt to woo business, etc. In actuality, the TP, in my opinion, is an attempt to outline a "set of possibilities," or "window" for tomorrow and provide steps for "entering it" in time. As for the TP "Post-genomic and Cell Technologies in Biology and Medicine," there are some simple things it could do:

Determine the direction of development in biotechnology on a global scale in the next 20 years and the choice of priorities for Russia;

Determine the best existing core competencies in Russia, as well as missing or poorly developed ones;
Generate proposals for supporting the best of the selected core competencies, as well as proposals for changing, enhancing, or closing the weak ones and, if necessary, developing new ones from scratch;

Generate proposals for improving the legislative and regulatory framework, and ensure that promotion of the selected competencies is free and transparent;

Help with the formation of the best competencies into distinct projects, help in linking projects to investors, support of projects after investment, and lobbying for the supported projects;

Identifying the competencies (persons, scientific groups) that cannot be packaged as projects but are advanced scientifically and can yield breakthroughs in a few years.

Assistance for such projects is possible through the formation of an environment with the most favorable conditions - financial (grants, non-performing loans, etc.) and organizational support (establishment of laboratories under project leaders at the Institutions of the RAS, RAMS, Universities). 
In addition, two other platforms are associated with biology, an area that is on the rise and is growing rapidly.

The idea only emerged two months ago on creating a platform for "Post-genomic and Cell Technologies in Biology and Medicine." Since this time, much work has been done. The Action Team conducted a survey of experts who recommended participants in the TP and identified the main problems. A memorandum has been prepared, and it was signed by 20 companies. The goals of this TP are scientifictechnological and innovative development of post-genomic and cell technologies for appropriate development of the Russian economy; improvement of the normative-legal regulation in this area; and consolidation of the Russian medical and biotechnological community to lobby its interests. The goal for the near future is to be included on the list of Russian TPs.

The "Industrial Biotechnologies and Bioenergetics" TP was initiated by the public corporation Ros-technologies. Its importance was stated by Vladimir Popov in these words: "While the rest of the world is focused on the creation of a bio economy, which is set to define the XXI century, Russia lacks any official high-level documents governing the development of biotechnologies. Biotechnologies will account for up to $3 \%$ of total GDP in developed countries, according to experts."

"Russia lost its biotechnological economy during the last 20 years, although it had been second only to the U.S. prior to the advent of Perestrojka," Popov said. Now Russia lags far behind on the international market, with a tiny market worth 2 billion dollars (which is $0.2 \%$ of the world market).

"The participants in the technology platform aim to steer development in this direction. Our aim is to consolidate the biotechnological community and lobby its interests at all levels of government," Popov says. At present, about 30 organizations are on the list of this TP. A memorandum has been developed. The next steps are expanding the list of participants, identifying possible sources of funding, preparing the conception of development, and being included in the Russian Federal TPs.

\section{HOW MANY PLATFORMS CAN BE DEVELOPED}

The federal TP list is currently under development. It is clear that the TPS that are in line with the set priorities in technological development are at the top of the list, as claimed in the document Conception of Long-term Development up to 2020 in Russia. Among them are the creation of next-generation aircraft and energyefficient engines, the construction of safer nuclear power plants, the development of hydrogen-based energy sources and production of new motor fuels, the development of optoelectronics and micromechanics, special equipment design for the Arctic and other extreme environments, and the development of new technologies for metal processing.

The Ministry of Economic Development continued to accept proposals for the creation of platforms until November 25, 2010. The approved projects, after they have been reviewed in cabinet offices, will be sent over for approval to a Government Commission workgroup. The selected platforms have not been announced yet. Experts have opined that about $10-15$ projects will be approved.
Alexander Gabibov, professor, corresponding member of RAS:

The creation of novel structures or new "communication tools" makes sense only if old ones operate poorly or require radical improvement. It is obvious that the new form, virtually developed rather recently in the Western world, can result in the creation of novel products, but only until three main components, i.e., science, production, and management, adopt equally competent approaches in solving problems. Only equal development of these three components can provide stable growth of the economy; otherwise, the idea of platforms will lose its shine. Unfortunately, prerequisites exist for such a pessimistic forecast. While the level of scientific research in Russia, which is constantly under criticism, can be evaluated in each particular case using internationally accepted benchmarks, the evaluation of the two other components is substantially more difficult. Our biotechnology business is extremely backward, and the quality of management doesn't stand scrutiny at all. The results of scientific research can be chosen quite consciously. However, those who moved into the biotechnological business are mostly former academic misfits who lack advanced training and are poorly equipped to work with staff. Unfortunately, this is obvious at various scientific and practical conferences, seminars, forums, and exhibitions. People are involved in promoting well-known products which can hardly be characterized as innovative. Only competent staff able to solve problems relating to the training of production managers, biotechnology engineers, and biotechnological production managers competent in manufacturing can make the TP program a reality. 